\title{
Estradiol, Obesity and Hypogonadism
}

\author{
Luboslav STÁRKA ${ }^{1}$, Martin HILL ${ }^{1}$, Hana POSPÍŠILOVÁ ${ }^{1}$, Michaela DUŠKOVÁ ${ }^{1}$ \\ ${ }^{1}$ Institute of Endocrinology, Prague, Czech Republic
}

Received December 18, 2019

Accepted February 12, 2020

\begin{abstract}
Summary
Obesity increases the incidence of hypogonadism in men, and hypogonadism in turn plays a role in obesity. One of the first mechanisms proposed to explain this was a hypothesis based on the principle that obese men have higher estrogen levels, and that increased estrogens provide feedback to the hypothalamicpituitary-testicular axis, reducing the secretion of gonadotropins and leading to a decrease of overall testosterone levels. This concept has since been questioned, though never completely disproven. In this study we compared hormone levels in three groups of men with differing BMI levels (between 18-25, 25-29, and 30-39), and found correlations between lowering overall testosterone, SHBG and increased BMI. At the same time, there were no significant changes to levels of free androgens, estradiol or the gonadotropins LH and FSH. These findings are in line with the idea that estrogen production in overweight and obese men with BMI up to $39 \mathrm{~kg} / \mathrm{m}^{2}$ does not significantly influence endocrine testicular function.
\end{abstract}

\section{Key words}

Obesity • Hypogonadism • Testosterone • SHBG • Estradiol

\section{Corresponding author}

L. Stárka, Institute of Endocrinlogy, Národní 8, 10000 Prague 1, Czech Republic. E-mail: Istarka@endo.cz

\section{Introduction}

Obesity is currently a worldwide problem, and not just in countries with high living standards but also in economically developing billion-plus populations like India and China (Fui et al. 2014). The incidence of obesity is often associated with other diseases of civilization such as diabetes, metabolic syndrome, and cardiovascular diseases (Vaverková et al. 2015, Kaprinay et al. 2016, Poledne et al. 2015, Rácz et al. 2018), along with comorbidities such as non-alcoholic liver steatosis (Toriniwa et al. 2018), osteoarthritis, and some oncological diseases.

Another disorder associated with obesity is hypogonadism, which affects almost a third of obese men (Dhinsa et al. 2018, Schulster et al. 2016). However, complicating this relationship, deficiencies in testicular function have been found even in overweight men, and besides age, obesity is the also the most common cause of male hypogonadism (Carrageta et al. 2019). Thus, the relationship between obesity and hypogonadism is multifactorial and bilateral, with obesity worsening hypogonadism, and on the other hand hypogonadism increasing obesity through androgen insufficiency. The decreased testicular production of androgens results in declines in fertility, sexual dysfunction, decreased muscle mass, changes to bone mineralization, and lipid metabolism disorders, as well as increasing fat deposition, increasing BMI and contributing to obesity (Pivonello et al. 2019, Grossmann 2018, Grossmann et al. 2019).

A clear worsening of metabolic indicators has repeatedly been demonstrated in patients treated for prostate cancer using androgen deprivation, with the testicular production of testosterone blocked through antagonists of gonadotropin-releasing hormones. Undesirable side effects of such treatment include the increased deposition of visceral fat and increased insulin resistance. Hypogonadism thus promotes various mechanisms leading to the production and deposition of fat (Grossmann 2018).

Androgens also play an important role in the regulation of body fat distribution in humans. They exert direct effects on adipocyte differentiation, size, and fat compartment expansion. Androgens directly impact key adipocyte functions including insulin signaling, lipid 
metabolism, fatty acid uptake and adipokine production (O'Reilly et al. 2014, Dušková and Pospíšilová 2011). On the other hand, with increased obesity a series of other factors lower the production of testosterone, thus creating a feedback loop that worsens the overall status. Among the predicted pathogenic mechanisms in this feedback loop are declines in SHBG caused by insulin resistance and proinflammatory cytokines. Declines in SHBG also lead to higher levels of free testosterone, which likely leads to the increased aromatization of testosterone in fatty tissues and increases in estrogens. Estrogens both decrease the production of gonadotropin-releasing hormones through a negative feedback loop and lead to the reduced production of testosterone, as well as promoting the deposition of fat. This hypothesis was first described by Cohen (1999), with decreases in overall testosterone being at least partially the result of decreased SHBG and thus increased levels of free testosterone. This should lead to the higher availability of free testosterone for the enzyme aromatase, which converts testosterone to estradiol and androstenedione to estrone. Higher estrogen levels could then impact the hypothalamic-pituitarygonadal axis and in men lead to an overall decrease in testosterone production. Higher estrogen levels in obese men have been repeatedly demonstrated (Jensen et al. 2004, Aggerholm et al. 2008, Ramlau-Hansen et al. 2010, Tunc et al. 2011, Fejes et al. 2006, Pauli et al. 2008, Chavarro et al. 2010), but other studies have found no increased estrogens or no correlation with BMI (Dhindsa et al. 2018, Wang et al. 2014, Pasquali et al. 1991). This is one reason why the concept of lowered testosterone resulting from increased conversion to estrogens has been criticized, though not yet completely disproven.

Other complicating factors include the direct inhibition of leptin function in Leydig cells or the possibility of lowered gonadotropin secretion resulting from several factors linked to obesity such as leptin and/or insulin resistance or increased inflammatory markers (Fuj et al. 2014, Pivonello et al. 2019). Decreased spermatogenesis in obese men can also be influenced by increased scrotal temperatures because of body tissue distribution and a lack of movement. The degree to which obesity influences the levels of sex hormones, spermiogram parameters and sperm DNA integrity is extremely variable in light of the multifactorial causes and related comorbidities (Kahn and Brannigan 2017).

Estrogens also play a role in food intake and energy (Xu and López 2018) as well as in male reproductive function (Schulster et al. 2016). In men, estradiol is essential for modulating libido, erectile function, and spermatogenesis. Estrogen receptors and aromatase, the enzyme that converts testosterone to estradiol, are abundant in brain, penis, and testis. In the brain, estradiol synthesis is increased in areas related to sexual arousal. In addition, estrogen receptors are found in the penis throughout the corpus cavernosum, with high concentrations around neurovascular bundles. Low testosterone and elevated estrogens increase the incidence of erectile dysfunction independently of one another. In the testes, spermatogenesis is modulated at every level by both testosterone and estrogen (Schulster et al. 2016).

In this study we aimed to explore the association of estrogens with body mass index in both obese and overweight men compared to controls, in continuation of our previous study on androgens and obesity (Pospíśilová et al. 2013).

\section{Materials and Methods}

\section{Subjects}

A total of 224 healthy men (except for their obesity and associated symptoms) aged 20 to 78 with a broad range of body mass index (BMI) from 18 to 39 were enrolled. All patients signed informed consent forms before taking part in the study. Blood withdrawal and anthropomorphic data were obtained from fasting subjects in the morning between 7:30 and 8:30 a.m. Blood was taken from the forearm vein and serum was stored at $-80^{\circ} \mathrm{C}$ until processed in the laboratory. Body height (to the nearest $\mathrm{cm}$ ) and weight (to the nearest $0.1 \mathrm{~kg}$ ) were used to calculate BMI as the weight $(\mathrm{kg})$ divided by height squared $\left(\mathrm{m}^{2}\right)$.

The men were then divided into three subgroups according to BMI. The first subgroup consisted of 109 men with BMI between 18 and 25 (controls), the second group included 78 men with BMI between 25 and 30 (considered overweight), and the third subgroup had 37 men with BMI 30 to 39 (considered obese).

\section{Hormone analysis}

Laboratory analyses of sex hormone binding globulin (SHBG), LH, FSH and steroid hormones were carried out as follows:

Serum total testosterone was determined by a standard radioimmunoassay (RIA) using antiserum antitestosterone-3-carboxymethyloxime:BSA and testosterone- 
3-carboxymethyloxime-tyrosylmethyl-ester-[125I] as a tracer. Intra-assay and inter-assay coefficient variants were $7.2 \%$ and $10 \%$, respectively, and sensitivity was $0.21 \mathrm{nmol} / 1$. Sex hormone binding globulin was assayed using an IRMA (Orion, Espoo, Finland). Estradiol was determined using the commercial kit ESTR-US-CT (Cisbio Bioassays, Codolet, France, distributor Solupharm, Czech Republic) for male concentrations with an interval of reference $34-226 \mathrm{pmol} / 1$ (0.025 and 0.975 percentile), mean recovery $102 \%$. Cross-reaction with estrone was $0.97 \%$, and the limit of detection was 5 pmol/1. Commercial IRMA (Beckman-Coulter) were used for the determination of FSH (analytical sensitivity $0.17 \mathrm{IU} / 1$, intra-assay $4.05 \%$ ) and LH (analytical sensitivity $0.16 \mathrm{IU} / 1$, intra-assay $7.33 \%$ ).

\section{Statistical data analysis}

To evaluate the relationships between dependent variables, we used an ANCOVA model with BMI group as the main factor and age of the subject as a covariate (i.e. an age-adjusted ANOVA), followed by least significant difference (LSD) multiple comparisons. The original dependent variables and the covariate were transformed by power transformations to attain a constant variance and symmetric distribution of the data and residuals (Meloun et al. 2000). The statistical software Statgraphics Centurion version XVI (Herndon, VA, USA) was used for the calculations. The homogeneity of the data and residual were checked as described elsewhere (Meloun et al. 2002).

\section{Results}

The differences in estradiol levels between the groups are listed in Table 1. Though there was a relative increase of $10 \%$ in the levels of estradiol in obese men compared to controls $(\mathrm{BMI}<25)$, this difference was not significant. In the overweight group there was even a decrease compared to controls, but again this was not significant.

Table 1. Relative values and relative decreases of hormones in the three groups with different BMI, as compared to the BMI $<25\left[\mathrm{~kg} / \mathrm{m}^{2}\right]$ group.

\begin{tabular}{|c|c|c|c|c|}
\hline \multirow[b]{2}{*}{ Variable } & \multirow[b]{2}{*}{ Unit } & \multirow[b]{2}{*}{$\begin{array}{c}\text { BMI } \\
{\left[\mathrm{kg} / \mathrm{m}^{2}\right]}\end{array}$} & \multicolumn{2}{|c|}{ Re-transformed means with $95 \%$ confidence intervals } \\
\hline & & & $\begin{array}{c}\text { Relative values } \\
\text { as compared to the } \mathrm{BMI}<25 \\
{\left[\mathrm{~kg} / \mathrm{m}^{2}\right] \text { group }} \\
{[\%]}\end{array}$ & $\begin{array}{c}\text { Relative decrease } \\
\text { as compared to the BMI }<25 \\
{\left[\mathrm{~kg} / \mathrm{m}^{2}\right] \text { group }} \\
{[\%]}\end{array}$ \\
\hline \multirow[t]{3}{*}{ Testosterone } & $\mathrm{nmol} / 1$ & $<25$ & $100(91.9,108)$ & $0(-8.4,8.1)$ \\
\hline & & $25-30$ & $84.8(76.6,93.4)$ & $15.2(6.6,23.4)$ \\
\hline & & $>30$ & $70.4(60.6,80.9)$ & $29.6(19.1,39.4)$ \\
\hline \multirow[t]{3}{*}{$S H B G$} & $\mathrm{nmol} / \mathrm{l}$ & $<25$ & $100(89.3,112)$ & $0(-12.3,10.7)$ \\
\hline & & $25-30$ & $81.6(72.1,92.7)$ & $18.4(7.3,27.9)$ \\
\hline & & $>30$ & $70.8(60.2,84.5)$ & $29.2(15.5,39.8)$ \\
\hline \multirow[t]{3}{*}{$100 \times$ Testosterone $/ \mathrm{SHBG}$} & & $<25$ & $100(90.7,110)$ & $0(-10.1,9.3)$ \\
\hline & & $25-30$ & $99.1(88.5,111)$ & $0.9(-10.9,11.5)$ \\
\hline & & $>30$ & $100(84.7,118)$ & $0(-17.7,15.3)$ \\
\hline \multirow[t]{3}{*}{$L H$} & $\mathrm{IU} / 1$ & $<25$ & $100(90.4,110)$ & $0(-10.4,9.6)$ \\
\hline & & $25-30$ & $102(91,115)$ & $-2.4(-14.9,9)$ \\
\hline & & $>30$ & $123(104,144)$ & $-23.1(-44.3,-4.3)$ \\
\hline \multirow[t]{3}{*}{ FSH } & $\mathrm{IU} / 1$ & $<25$ & $100(86,116)$ & $0(-16,14)$ \\
\hline & & $25-30$ & $107(90.3,128)$ & $-7.5(-27.5,9.7)$ \\
\hline & & $>30$ & $115(89.6,147)$ & $-15.5(-47.5,10.4)$ \\
\hline \multirow[t]{3}{*}{ Estradiol } & $\mathrm{pmol} / 1$ & $<25$ & $100(88.4,112)$ & $0(-12.5,11.6)$ \\
\hline & & $25-30$ & $90.8(78.1,105)$ & $9.2(-4.7,21.9)$ \\
\hline & & $>30$ & $110(90.1,133)$ & $-10.3(-33,9.9)$ \\
\hline
\end{tabular}



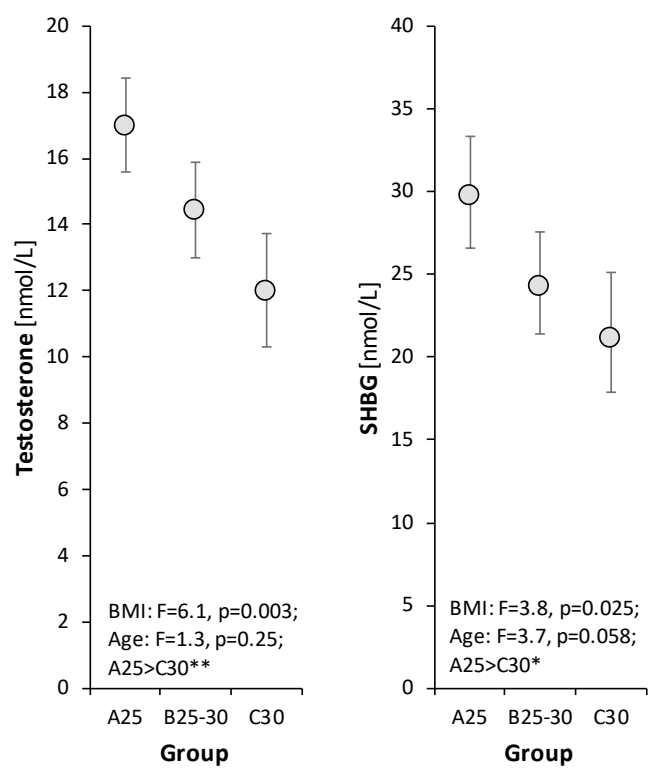

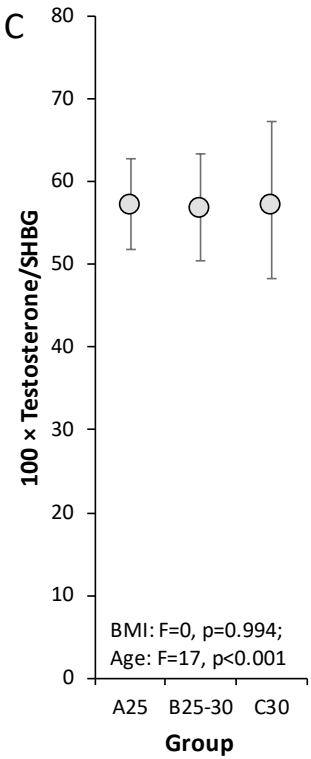

Fig. 1. Relationships between levels of total testosterone, SHBG, free testosterone index $(100 \times$ testosterone/SHBG) and BMI as evaluated by the age-adjusted ANCOVA model followed by Bonferroni multiple comparisons. The circles with error bars show age-adjusted group re-transformed means with $95 \%$ confidence intervals (after Bonferroni correction). The original data were transformed by Box-Cox transformation to attain data symmetry and homoscedasticity before statistical testing, and the obtained transformed means and their confidence limits were retransformed to the original scale for illustration. $F$ and $p$ are Fisher's statistic and p-value, respectively in ANCOVA testing. Bonferroni multiple comparisons $* p<0.05$, $* * \mathrm{p}<0.01$.
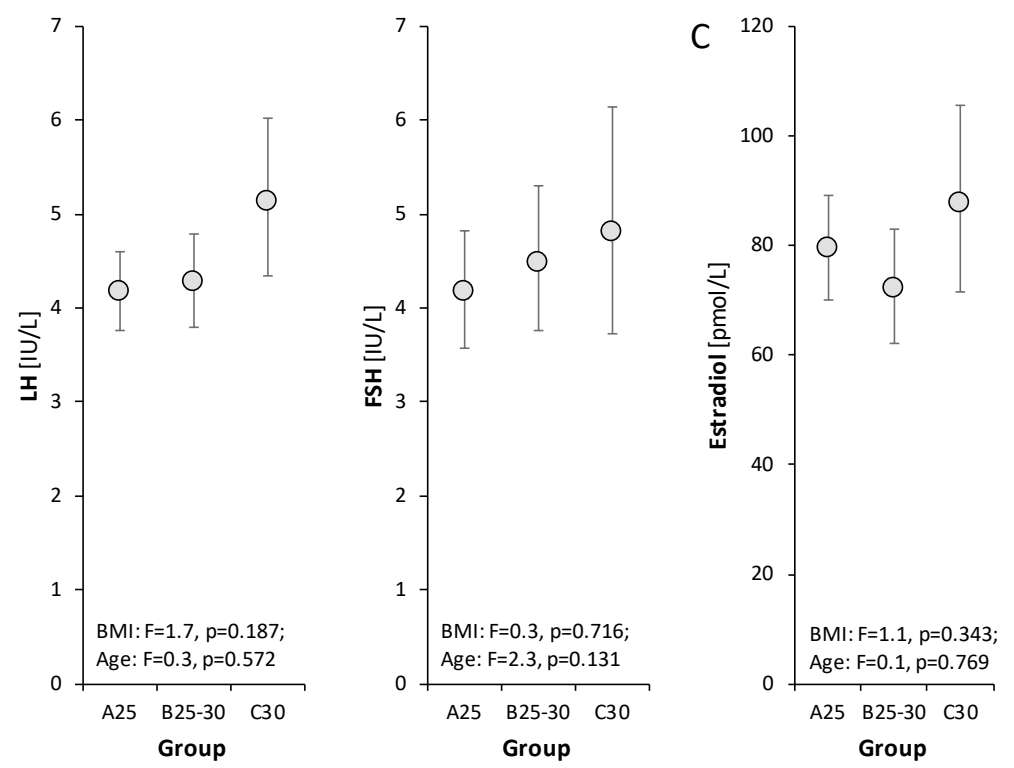

Fig. 2. Relationships between levels of $\mathrm{LH}, \mathrm{FSH}$, estradiol and BMI as evaluated by the ageadjusted ANCOVA model followed by Bonferroni multiple comparisons. The drawings and symbols are the same as for Figure 1 .

In comparison with controls, obese and

\section{Discussion}

overweight patients had significantly lower not only levels of total testosterone but also of SHBG, and in consequence the free androgen index (FAI $=$ [total testosterone/SHBG] $\mathrm{x}$ 100) was in the normal range (Fig. 1).

Total testosterone differed significantly between overweight and obese men, whereas SHBG differed significantly between controls and overweight men, but not between overweight and obese men.

Levels of FHS and LH showed no significant differences among the groups, though there was a slight tendency toward higher levels in obese men (Fig. 2). Therefore, the hypothalamic-pituitary-testicular axis did not seem to be markedly influenced by BMI levels up to $30 \mathrm{~kg} / \mathrm{m}^{2}$.

The hypothesis that reduced testosterone levels in obese men are the result of higher estrogen production and effects on the hypothalamic-pituitary-testicular axis was based on the fact that slightly higher estrogen levels have been found in obese men compared to those of normal BMI. For instance, Aggerholm et al. (2008) found that total testosterone serum concentrations were 25-32\% lower in obese men in comparison with normal-weight men, whereas estradiol concentrations were $6 \%$ higher (Aggerholm et al. 2008). In another study (RamlauHansen et al. 2010), men with high adulthood BMI had $14 \%$ lower testosterone, $9 \%$ lower inhibin B, $31 \%$ lower SHBG, and $20 \%$ higher estradiol than men with 
low adulthood BMI. Pauli et al. (2008) found that BMI was positively correlated with estradiol $(\mathrm{R}=0.34$, $\mathrm{P}=0.001$ ), though for men with $\mathrm{BMI}$ in the range 20-30 this correlation was insignificant. Chavarro et al. (2010) found a total testosterone decrease with increasing BMI, though estradiol concentrations did not differ between lean (estradiol, 29.5 [22.5-38.0] pg/ml) and overweight men $(29.0$ [21.5-35.0] pg/ml), and only a small increase was observed in obese men (33.5 [23.0-38.0] pg/ml).

We found similar relative changes in estradiol levels, with higher levels in obese men by $10.3 \%$ and lower levels in overweight men by $9.2 \%$ compared to men with BMI from 18-25. However, these differences were not significant. Other studies have also found no correlation between estradiol and body mass (e.g. Pasquali et al. 1991, Wang et al. 2014, Dhindsa et al. 2018). Similarly, in women with polycystic ovarian disease, no significant correlation was found between estradiol levels and body mass, though estrone levels did significantly increase with increased mass (Lazúrová et al. 2019). The study of Pasquali et al. (1991) found similar results for estrone in men.

In all these studies, estradiol levels were within reference ranges. Even though in cases of extreme obesity there is a demonstrable increase in estradiol, this does not explain the quantitatively deep declines of testosterone in obese men with hypogonadism.

On order for the hypothesis that total testosterone declines in obese men are initiated by increases of estradiol levels to be correct, there would have to be significant increases in estradiol. This has yet to be conclusively demonstrated, and our results do not support this either. And even if an increase in estradiol was found, it has yet to be shown that its influence on the function of the hypothalamic-pituitary-gonadal axis would be such that obesity could cause hypogonadism through this pathway. Levels of the gonadotropins LH and FSH in our study support the idea that gonadotropin secretion is not suppressed with increased body mass. This is also supported by clinical experience that has found that aromatase inhibitors and selective modulators of estrogen receptors (SERM) do not markedly improve the status of obese men with hypogonadism (Grossmann 2018).

\section{Conflict of Interest}

There is no conflict of interest.

\section{Acknowledgements}

Supported by Ministry of Health CR, RVO (Institute of Endocrinology - EU, 00023761).

\section{References}

AGGERHOLM AS, THULSTRUP AM, TOFT G, RAMLAU-HANSEN CH, BONDE JP: Is overweight a risk factor for reduced semen quality and altered serum sex hormone profile? Fertil Steril 90: 619-626, 2008. https://doi.org/10.1016/j.fertnstert.2007.07.1292

CARRAGETA DF, OLIVEIRA PF, ALVES MG, MONTEIRO MP: Obesity and male hypogonadism: tales of a vicious cycle. Obes Rev 20: 1148-1158, 2019. https://doi.org/10.1111/obr.12863

CHAVARRO JE, TOTH TL, WRIGHT DL, MEEKER JD, HAUSER R: Body mass index in relation to semen quality, sperm DNA integrity, and serum reproductive hormone levels among men attending an infertility clinic. Fertil Steril 93: 2222-2231, 2010. https://doi.org/10.1016/j.fertnstert.2009.01.100

COHEN PG: The hypogonadal-obesity cycle: role of aromatase in modulating the testosterone-estradiol shunt a major factor in the genesis of morbid obesity. Med Hypotheses 52: 49-51, 1999. https://doi.org/10.1054/mehy.1997.0624

DHINDSA S, GHANIM H, BATRA M, DANDONA P: Hypogonadotropic hypogonadism in men with diabesity. Diabetes Care 41: 1516-1525, 2018. https://doi.org/10.2337/dc17-2510

DUŠKOVÁ M, POSPÍŠILOVÁ H: The role of non-aromatizable testosterone metabolite in metabolic pathways. Physiol Res 60: 253-261, 2011. https://doi.org/10.33549/physiolres.932080

FEJES I, KOLOSZÁR S, ZÁVACZKI Z, DARU J, SZÖLLÖSI J, PÁL A: Effect of body weight on testosterone/estradiol ratio in oligozoospermic patients. Arch Androl 52: 97-102, 2006. https://doi.org/10.1080/01485010500315479

FUI MNT, DUPUIS P, GROSSMANN M: Lowered testosterone in male obesity: mechanism, morbidity and management. Asian J Andrology 16: 223-231, 2014. https://doi.org/10.4103/1008-682X.122365 
GROSSMANN M: Hypogonadism and male obesity. Focus on unresolved questions. Clin Endocrinol (Oxf) 89: 11-21, 2018. https://doi.org/10.1111/cen.13723

GROSSMANN M, FUI MNT, CHEUNG AS: Late onset hypogonadism: metabolic impact. Andrology 2019: 1-11, 2019. https://doi.org/10.1111/andr.12705

JENSEN TK, ANDERSSON AM, JØRGENSEN N, ANDERSEN AG, CARLSEN E, PETERSEN JH, SKAKKEBAEK NE: Body mass index in relation to semen quality and reproductive hormones among 1,558 Danish men. Fertil Steril 82: 863-870, 2004. https://doi.org/10.1016/j.fertnstert.2004.03.056

KAPRINAY B, LIPTÁK B, SLOVÁK L, ŠVÍK K, KNEZL V, SOTNÍKOVÁ R, GÁSPÁROVÁ Z: Hypertriglyceridemic rats fed high fat diet as a model of metabolic syndrome. Physiol Res 65 (Suppl 4): S515-S518, 2016. https://doi.org/10.33549/physiolres.933524

LAZÚROVÁ I, LAZÚROVÁ Z, FIGUROVÁ J, UJHÁZI S, DRAVECKÁ I, MAŠLANKOVÁ J, MAREKOVÁ M: Relationship between steroid hormones and metabolic profile in women with polycystic ovary syndrome. Physiol Res 68: 457-465, 2019. https://doi.org/10.33549/physiolres.934062

MELOUN M, HILL M, MILITKY J, KUPKA K: Transformation in the PC-aided biochemical data analysis. Clin Chem Lab Med 38: 553-559, 2000. https://doi.org/10.1515/CCLM.2000.081

MELOUN M, MILITKY J, HILL M, BRERETON RG: Crucial problems in regression modelling and their solutions. Analyst 127: 433-450, 2002. https://doi.org/10.1039/b110779h

O'REILLY MW, HOUSE PJ, TOMLINSON JW: Understanding androgen action in adipose tissue. J Steroid Biochem Mol Biol 143: 277-284, 2014. https://doi.org/10.1016/j.jsbmb.2014.04.008

PASQUALI R, CASIMIRRI F, CANTOBELLI S, MELCHIONDA N, MORSELLI LABATE AM, FABBRI R, CAPELLI M, BORTOLUZZI L: Effect of obesity and body fat distribution on sex hormones and insulin in men. Metabolism 40: 101-104, 1991. https://doi.org/10.1016/0026-0495(91)90199-7

PAULI EM, LEGRO RS, DEMERS LM, KUNSELMAN AR, DODSON WC, LEE PA: Diminished paternity and gonadal function with increasing obesity in men. Fertil Steril 90: 346-351, 2008. https://doi.org/10.1016/j.fertnstert.2007.06.046

PiVONELlO R, MENAFRA D, RICCIO E, GARIFALOS F, MAZZELla M, DE ANGELIS C, COLAO A: Metabolic disorders and male hypogonadotropic hypogonadism. Front Endocrinol 10: 345, 2019. https://doi.org/10.3389/fendo.2019.00345

POSPISILOVA H, DUSKOVA M, HILL M, HORAK L: Changes of steroidogenesis subject to weight growth. ECE 2013 Copenhagen, http://www.endocrine-abstracts.org/ea/0032/ea0032p976.htm. https://doi.org/10.1530/endoabs.32.P976

RÁCZ B, DUŠKOVÁ M, STÁRKA L, HAINER V, KUNEŠOVÁ M: The link between circadian rhytm, obesity and microbiome. Physiol Res 67 (Suppl 3): S409-S420, 2018. https://doi.org/10.33549/physiolres.934020

RAMLAU-HANSEN CH, HANSEN M, JENSEN CR, OLSEN J, BONDE JP, THULSTRUP AM: Semen quality and reproductive hormones according to birth weight and body mass index in childhood and adult life: two decades of follow-up. Fertil Steril 94: 610-618, 2010. https://doi.org/10.1016/j.fertnstert.2009.01.142

SCHULSTER M, BERNIE AM, RAMASAMY R: The role of estradiol in male reproductive function. Asian J Androl 18: 435-440, 2016. https://doi.org/10.4103/1008-682X.173932

TORINIWA Y, MURAMATSU M, ISHII Y, RIYA E, MIYAJIMA K, OHSHIDA S, KITATANI K, TAKEKOSHI S, MATSUI T, KUME S, YAMADA T, OHTA T: Pathophysiological characteristics of non-alcoholic steatohepatitis-like changes in cholesterol-loaded type 2 diabetic rats. Physiol Res 67: 601-612, 2018. https://doi.org/10.33549/physiolres.933784

TUNC O, BAKOS HW, TREMELLEN K: Impact of body mass index on seminal oxidative stress. Asian J Androl 43: 121-128, 2011. https://doi.org/10.1111/j.1439-0272.2009.01032.x

VAVERKOVÁ H, KARÁSEK D, NOVOTNÝ D, HALENKA M, ORSÁG J, SLAVÍK L: Hypertriglyceridemic waist a simple clinical tool to detect cardiometabolic risk: comparison with harmonized definition of metabolic syndrome. Physiol Res 64 (Suppl 3): S385-S394, 2015. https://doi.org/10.33549/physiolres.933198

WANG N, ZHAI H, HAN B, LI Q, CHEN Y, CHEN Y, XIA F, LIN D, LU Y: Visceral fat dysfunction is positively associated with hypogonadism in Chinese men. Sci Rep 6: 19844, 2016. https://doi.org/10.1038/srep19844 